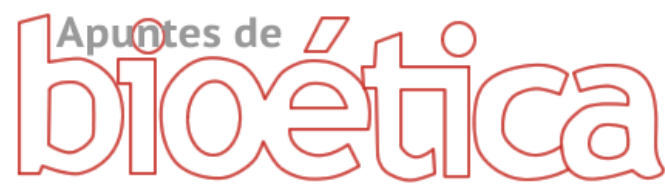

https://doi.org/10.35383/apuntes.v1i1.197

\title{
David vs. Goliat (Caso Planned Parenthood y la venta de órganos de bebés abortados): La pendiente resbaladiza de la legalización del aborto
}

\author{
Mirielle Liliana Palacios Yabar ${ }^{1}$
}

Un análisis bioético y biojurídico de una de las consecuencias de la legalización del aborto en torno al tráfico de órganos fetales obtenidos de abortos para investigación biomédica.

\section{INFORMACIÓN DEL ARTÍCULO RESUMEN}

Recibido el 29 de setiembre de 2018

Aceptado el 21 de noviembre de 2018

\section{Palabras claves:}

Venta de tejido fetal humano

Planned Parenthood

David Daleiden

Industria de tejidos fetales humanos

Industria del aborto

Legalización del aborto

Centro para el Progreso Médico

Capital Humano
Tras la legalización del derecho constitucional de la mujer al aborto en Estados Unidos con el caso Roe vs. Wade, se abrió la puerta a muchas consecuencias que esta decisión trajo consigo. Una de estas consecuencias es la venta ilegal de órganos y tejidos extraídos en abortos. En el presente artículo se desarrollará un análisis bioético y biojurídico del caso que trajo a la luz esa pendiente resbaladiza de la legalización del aborto, este es, el caso de la investigación de la organización sin fines de lucro, Center for Medical Progress (CMP) a la multinacional del aborto, Planned Parenthood, y la consecuente investigación y reporte final presentado por el Panel Selecto.

David vs. Goliath (Case Planned Parenthood and the selling of aborted baby body tissues): The slippery slope of abortion legalization

${ }^{1}$ Licenciada en Farmacia y Bioquímica en la Universidad Peruana Cayetano Heredia. Diplomada en Inmunología Básica y Clínica en la Universidad Peruana Cayetano Heredia. Diplomada en Bioética en la Investigación Biomédica y Clínica en la Universidad Católica Santo Toribio de Mogrovejo. Analista de Farmacovigilancia. Email: mirielle.palacios@gmail.com. ORCID: https://orcid.org/0000-0001-9614-6036 


\section{ABSTRACT}

\section{Keywords:}

Sale of Human fetal tissue

Planned Parenthood

David Daleiden

human fetal tissue industry

abortion industry

abortion legalization

Center for Medical Progress

Human Capital

\begin{abstract}
After the legalization of the constitutional right of women to abortion in the United States with the case Roe vs. Wade, the door was opened to many consequences that this decision brought with it. One of these consequences is the illegal sale of organs and tissues extracted in abortions. In the present article a bioethical and biolegal analysis will be developed of the case that brought to light that slippery slope of the legalization of abortion, this is the case of the research of the non-profit organization, Center for Medical Progress (CMP) to the multinational abortion, Planned Parenthood, and the consequent investigation and final report presented by the Select Panel of the Committee on Energy and Commerce of the US House of Representatives
\end{abstract}

\section{Introducción}

Un hito relevante, que sentó precedente en el debate del aborto, es el caso Roe vs. Wade (410 US 113) (Blackmun \& Supreme Court of the United States, U.S. Reports: Roe v. Wade 410 U.S. 113, 1972), ocurrido en la Corte Suprema de Estados Unidos entre 1971 y 1973, el cual abrió paso a declarar que la prohibición del aborto era inconstitucional para la mujer en ese mismo país.

El caso se desarrolló en Dallas County, Texas, donde una mujer embarazada soltera, que nombraron "Jane Roe", demandó al estado, en su nombre y a nombre de otras mujeres en situaciones similares, al no poder obtener un aborto legal en la jurisdicción en la que se encontraba ya que su vida no corría riesgo e indicó que al negarle esto, iba en contra de su derecho a la libertad y privacidad personal, el cual estaba protegido por las enmiendas 1, 4, 5, 9 y 14. En este caso intervino también el médico James Hubert Hallford, el cual había sido arrestado previamente por violar los estatutos del aborto en Texas (Blackmun \& Supreme Court of the United States, U.S. Reports: Roe v. Wade 410 U.S. 113, 1972) (Cornell University Law School, 1971-1973).

La Corte Suprema determinó por 7 votos contra 2 (Cornell's Legal Information Institute (LII), Roe v. Wade, s.f.), que "(...) el derecho fundamental para una mujer soltera y personas casadas de elegir si tener hijos, estaban ambos protegidos por las enmiendas 9 a la 14 (...)" (Cornell University Law School, 1971-1973), razón por lo cual los estados no podían regular los abortos durante el primer trimestre (Cornell's Legal Information Institute (LII), Roe v. Wade, s.f.), esto abrió el paso a lo que conocemos hoy como el "derecho a decidir". Sin embargo, se definió que después del primer trimestre, los estados si podían regular el procedimiento del aborto para proteger la salud de la madre y cuando había viabilidad del feto podían regular o prohibir el aborto (Blackmun \& Supreme Court of the United States, U.S. Reports: Roe v. Wade 410 U.S. 113, 1972) (Cornell University Law School, 1971-1973). 
A su vez, ese mismo día y junto a ese caso, la Corte Suprema también invalidó una ley de Georgia, como complemento de lo decidido en Roe vs Wade, que autorizaba el aborto sólo cuando se ponía en riesgo la salud y vida de la madre, lo cual incluyó: la salud mental de la madre, en caso el feto tenga defectos y cuando los embarazos hayan sido causados por violación. Este caso es el llamado Doe vs. Bolton (410 US 179) (Blackmun \& Supreme Court of the United States, U.S. Reports: Doe v. Bolton 410 U.S. 179, 1972), en el cual una pareja de esposos sin hijos, demandó al estado, por ellos y por las parejas que se encontraran en situaciones similares, a poder realizarse un aborto legal, en el caso la esposa quedara embarazada, al no estar tomando anticonceptivos y debido a ser diagnosticada con un trastorno neuro-químico, aunque el embarazarse no causaría un riesgo para su vida (Cornell University Law School, 1971-1973).

Entre 1991 y 1992, la Corte Suprema por un voto de 5 a 4 (Cornell's Legal Information Institute (LII), Planned Parenthood of Southeastern Pennsylvania v. Casey, s.f.), en el caso Planned Parenthood of Southeastern Pennsylvania vs. Casey (505 US 833) (O'Connor, Kennedy, Souter, \& Supreme Court of the United States, 1992), reafirmó la ley dada por Roe y la mayoría de requisitos de la ley del estado de Pensilvania ${ }^{2}$ excepto el requisito de que las mujeres debían notificar a sus esposos antes de un aborto, la cual la denominaron inconstitucional.

Adicionalmente, se reemplazó la decisión de Roe en la que los estados no podían regular el aborto antes del primer trimestre $\mathrm{y}$ se les permitió desde esa fecha regular el aborto desde

\footnotetext{
${ }^{2}$ Ley llamada Pennsylvania Abortion Control Act promulgada en 1982, incluía los siguientes requisitos para los abortos: una mujer casada debía notificar a su esposo antes de un aborto, se requería en consentimiento de al menos un padre en caso de menores de 18 años, las mujeres debían esperar 24 horas como un periodo de reflexión para la realización del aborto y las clínicas de abortos debían proveer estadísticas de los abortos realizados (Cornell's Legal Information Institute (LII), Planned Parenthood of Southeastern Pennsylvania v. Casey, s.f.).
}

que el feto alcance la viabilidad (O'Connor, Kennedy, Souter, \& Supreme Court of the United States, 1992) (Cornell's Legal Information Institute (LII), Planned Parenthood of Southeastern Pennsylvania v. Casey, s.f.).

Otro hito importante a resaltar es el caso de Stenberg vs. Carhart (530 US 914) (Breyer \& Supreme Court of the United States, 2000) en el 2000, en el que la Corte eliminó una ley de Nebraska que prohibía el aborto por nacimiento parcial por ser inconstitucional por un voto de 5 contra 4 (Cornell's Legal Information Institute (LII), Stenberg v. Carhart, s.f.). Sin embargo, en el 2007 con el caso Gonzales vs Carhart (550 US 124) (Cornell University Law School, 2006-2007) por 5 votos contra 4 (Cornell's Legal Information Institute (LII), Gonzales v. Carhart, s.f.), se determinó que la ley de prohibición del aborto por nacimiento parcial dictada por el Congreso y firmada por el Presidente en 2003, no era ambiguamente inconstitucional y no bloqueaba el derecho al aborto. La técnica fue definida en la misma ley como:

“(...) procedimiento en el cual el médico (A) deliberadamente e intencionalmente realiza un parto vaginal de un feto vivo hasta que, en caso de presentación de cabeza, la cabeza entera se encuentra fuera del cuerpo de la madre, o en caso de presentación de pies, cualquier parte del tronco fetal pasando el ombligo se encuentra fuera del cuerpo de la madre, con el propósito de realizar un acto en el cual la persona sabe que matará al feto nacido parcialmente: y (B) realiza el acto, aparte de completar el nacimiento, de matar al feto" (Cornell University Law School, 20062007).

Este procedimiento llamado también Dilatación y Evacuación Intacta, la cual deriva de la otra técnica de Dilatación y Evacuación, en que se obtiene el feto casi intacto y termina por atravesar o aplastar la cabeza una vez fuera del cuerpo de la madre, ha sido muy controversial por ser una práctica médica innecesaria, lo cual 
fue resaltado por la Corte en este caso (Cornell's Legal Information Institute (LII), Gonzales v. Carhart, s.f.).

Estos hitos enmarcan la regulación actual de Estados Unidos, que será la base de este artículo. Se desarrollará un análisis puntual acerca del dilema que se puede observar en Estados Unidos actualmente, después de 46 años de "Roe vs Wade" y la legalización del aborto, en cuanto a la venta de estos tejidos fetales para investigación biomédica, las consecuencias que se encontraron, así como los daños y atropellos que se cometen contra el mismo ser humano y contra las leyes y cómo ésta puede ser tomada como una pendiente resbaladiza del aborto.

La venta de tejidos fetales es un importante problema tanto legal como ético en la actualidad, ya que por más que tenga un fin noble, la búsqueda de mejores tecnologías biomédicas para el bienestar del ser humano, con el uso de tejidos fetales obtenidos de abortos provocados, no deja de ser un dilema bioético y legal que crea polémica $y$ controversias en todo el mundo.

Asimismo, en este artículo, se hará un análisis sólo de una de las consecuencias que hay tras la apertura del aborto, en específico la venta de órganos de fetos abortados voluntariamente para uso en investigaciones biomédicas, que a pesar de regirse bajo normas claras de prohibición de su compra-venta, se descubrió que se quebraron estas leyes presentadas.

La finalidad de este artículo no es hablar del aborto, ni ahondar en la parte jurídica de este, sino analizar una de las pendientes resbaladizas que aparecen tras la legalización del aborto en un caso estudiado de la actualidad como es el del Center for Medical Progress (CMP) vs Planned Parenthood (PP). Sin embargo, se usan ciertas referencias históricas, conceptuales y legales que ayudan a poner en contexto el análisis.

\section{Metodología}

El presente artículo tiene un enfoque cualitativo (Hernandez Sampieri, 2014, págs. 219), de tipo documental (Bernal, 2016, págs. 110-120), el cual se basa principalmente en la revisión del reporte final del Panel Selecto del Congreso de Estados Unidos y de los videos y material proporcionado por el Centro para el Progreso Médico (CMP), para poder hacer el análisis bioético y biojurídico del caso en base a esta información obtenida.

\section{Desarrollo de la investigación de Center for Medical Progress}

Desde Julio del 2015, un periodista de investigación, David Daleiden, fundador del "Center for Medical Progress (CMP)" (CThe Center for Medical Progress, 2015) o en español "Centro para el Progreso Médico", una organización sin fines de lucro, publicó videos producto de una exhaustiva investigación encubierta realizada por casi 3 años en el proyecto "Human Capital" (@The Center for Medical Progress, 2015) o "Capital Humano". En este proyecto, David Daleiden posó como la cabeza de una compañía interesada en el negocio de obtención de tejido fetal y filmó entrevistas con doctores, altos ejecutivos $y$ empleados de Planned Parenthood (PP), donde demostraba su vínculo con compañías como "Advanced Bioscience Resources", "DaVinci Biologics", "Novogenics y "StemExpress" para la obtención de tejidos fetales y su consecuente compra y venta.

Estos videos documentaron muchas horas de reuniones y conversaciones acerca de las prácticas dentro de clínicas de aborto locales y grupos afiliados a la industria de obtención de tejidos fetales, dando como resultado 14 videos 
resumen que se encuentran en la Página Oficial de CMP (CThe Center for Medical Progress, 2015) que fueron publicados y difundidos al finalizar la investigación. Los videos se publicaron entre el 14 de Julio del 2015 hasta el 27 de Julio del 2017. Sólo 11 de estos videos fueron incluidos en la investigación del Congreso de Estados Unidos ${ }^{3}$.

Dentro de los videos que fueron publicados, se puede observar a trabajadores de Planned Parenthood Federation of America (PPFA) admitiendo que los acuerdos de venta y obtención de tejidos fetales son rentables para las clínicas. En dichos videos, también se les puede ver admitiendo que en ocasiones cambiaban el procedimiento del aborto para obtener el material fetal más intacto e, incluso, que usaban el procedimiento de nacimiento parcial, el cual es aún ilegal en Estados Unidos. PPFA reveló también dentro de estos videos, que intencionalmente no habían implementado la política de remuneración, ya que esto sí llamaría la atención de los medios de comunicación (U.S. House of Representatives. Selective Investigative Panel of The Energy \& Commerce Committee, 2016, pág. xviii).

Ante la acusación y presentación de estos videos que demuestran ciertas prácticas ilegales e ilícitas, el Subcomité de Energía y Comercio del Congreso de Estados Unidos empezó una investigación ardua por tráfico de tejidos fetales, a través de un Panel Selecto creado el 07 de Octubre del 2015, el cual publicó un reporte final de todas sus investigaciones el 30 de Diciembre del 2016 con todos sus hallazgos y recomendaciones finales.

\footnotetext{
${ }^{3}$ Según lo informado por CMP, debido a una denuncia por parte de Planned Parenthood, CMP se vio obligado a detener la publicación de sus videos por una orden judicial. Sin embargo, para Diciembre del 2017, CMP solicitó se descalifique al juez que evaluaba el caso por existir un conflicto de intereses entre dicho juez y Planned Parenthood, al ser un donador frecuente a Planned Parenthood y brindarle su apoyo en diversas ocasiones. (@The Center for Medical Progress, 2015)
}

El Panel Selecto inició las investigaciones correspondientes y organizó dos audiencias públicas para examinar problemas críticos, estas fueron Ilamadas (1) Bioética y Tejido fetal y (2) El precio del tejido fetal.

Cabe resaltar que el Panel Selecto de Investigación no se enfocó en investigar los videos publicados y comprobar su veracidad, sino que investigó a la industria del aborto, incluyendo a las clínicas de abortos, entidades que obtienen los tejidos fetales e investigadores de Universidades. Los videos fueron tomados por el Panel Selecto como una acusación grave, reconociendo que el tráfico de tejido fetal para obtener ganancias o beneficios es una violación de las leyes (U.S. House of Representatives. Selective Investigative Panel of The Energy \& Commerce Committee, 2016, pág. 3).

\section{Conclusiones}

Existen muchas interrogantes que nacen a partir de este caso Planned Parenthood, las cuales fueron resaltadas en la investigación realizada por el Panel Selecto del Congreso, el cual concluyó que en muchas de sus clínicas afiliadas y en las empresas que obtenían tejidos fetales, las actividades realizadas en cuanto a la recolección de tejidos de fetos abortados voluntariamente, fueron no éticas e ilegales.

El Reporte final del Panel Selecto de Investigación concluyó: que nadie debería beneficiarse de la venta de tejidos fetales; que es inapropiado que alguien se embarace sólo con la intención de donar el tejido fetal para investigación; que el formato de consentimiento informado de PP no contenía información apropiada y debió haber sido observad por un Comité de Revisión Institucional (IRB). Adicionalmente concluye que no se han encontrado curas para enfermedades que requieran tejido fetal, por lo que incluir esto 
dentro del consentimiento sería coaccionar a las pacientes; además que los tejidos fetales no deberían ser usados para cosméticos ni para investigación del sabor en alimentos; y, es una decisión moral propia de la mujer el querer realizar o no la donación de tejido fetal después de un aborto, sea espontáneo o inducido, por lo que debería ser voluntaria y no coaccionada por ningún motivo (U.S. House of Representatives. Selective Investigative Panel of The Energy \& Commerce Committee, 2016, pág. 30).

Ya que la legalización del aborto según el Panel Selecto " (...) ha creado, a bajo costo, una fuente abundante de material fetal (...)" (Agulles Simó \& Gillén Pascual, 2011, pág. 168), las recomendaciones incluidas dentro de este reporte, si son tomadas en cuenta ayudarían a evitar futuras situaciones similares y enfocar la atención en la protección de las mujeres y de los niños, y podría ayudar a delimitar la actividad de estas empresas, así como a la investigación biomédica y la guiaría a obtener mejores resultados para la humanidad respetando la dignidad humana (May, 2013, págs. 44-45).

Después de la Investigación y presentación del Reporte Final, el Panel Selecto también presentó las demandas respectivas de cada infracción a los estados donde correspondiera, y colocó en manos de la justicia la decisión de qué medidas se deben tomar con los responsables de los crímenes descritos.

Recientemente el Congreso de Estados Unidos aprobó una legislación para "Repeler y Reemplazar" (Kaplan \& Pear, 2017) la ley de "Obamacare". Según lo indicado dentro del documento que reemplazaría "ObamaCare", el congreso de Estados Unidos (U.S Congress., 2017), incluye que se podría bloquear financiamientos federales a Planned Parenthood por un año. Esto, tal vez, podría considerarse como un indicativo que el Congreso en su totalidad pueda seguir las recomendaciones presentadas por el Panel Selecto, específicamente la de crear una ley explícita que permita a los estados el poder elegir no reembolsar a proveedores de abortos.

Al considerar todos estos detalles que se han analizado tras la investigación realizada por el Panel Selecto, quedan aún muchas interrogantes acerca de la venta de tejidos fetales abortados voluntariamente, tema muy controversial por correr el riesgo fomentar la práctica del aborto (Sgreccia, 2014, pág. 781) para lucrar con los mismos y por su cooperación formal con el mal (Agulles Simó \& Gillén Pascual, 2011, págs. 185193).

El avance de la ciencia debe ir de la mano con la protección y respeto de la dignidad de la persona, así como también de sus derechos. Si no existe un interés en salvaguardar estos y buscar el bienestar tanto del individuo como el de la sociedad, se cometen graves errores como los que podemos observar en el caso estudiado en este artículo. La comercialización de tejidos fetales, al romper principios éticos y leyes, ha sido una pendiente resbaladiza de la legalización del aborto, y con esta nos trae más interrogantes para el futuro, y quedaría preguntarnos si estamos realmente preparados para afrontar estos nuevos retos.

\section{Recomendaciones}

Después de la investigación realizada por el Panel Selecto, este elaboró recomendaciones para evitar que los mismos errores se sigan cometiendo. Los dividen en 3 categorías:

(1) Protección directa a mujeres y niños: El Panel recomienda al Congreso tomar medidas para asegurar la protección a todas las madres por medio del consentimiento de donación según la ley 42 U.S.C. § 289g-1(b) y (c), al mejorar la legislación aclarando la definición de "cambio de método del aborto". 
Además pide al Congreso asegurar que el Departamento de Salud y Servicios Humanos controle que el uso de consentimientos informados no sean engañosos y fraudulentos, que el Comité de Revisión Institucional (IRBs) tenga mejor actuación, que haya protección de la privacidad del paciente y entrenamientos a empleados que realizan abortos para el cuidado de niños nacidos vivos en abortos voluntarios.

A su vez, pide asegurar que el Departamento de Justicia castigue a todos los que lucran con estos tejidos fetales abortados y levante una prohibición de cruzar de un estado a otro para obtener tejidos fetales abortados si el estado prohíbe la donación de los mismos. Adicionalmente, recomienda crear una ley en la que incentive a los médicos a hacer todo su esfuerzo para que el niño nazca vivo en casos de embarazos de 20 semanas a más y que no se usen feticidas (como digoxina) ni desmembramiento en estos casos.

(2) Administración de fondos de los impuestos: El Panel recomienda retirar el financiamiento a Planned Parenthood y dárselo a otras entidades que brinden salud y no realicen abortos, excepto en ciertos casos como violación, incesto o algún trastorno que ponga en riesgo la vida de la madre. Además, recomienda al Congreso aprobar una ley explícita que permita a los estados excluir a los proveedores de abortos de recibir reembolsos de Medicad $^{4}$ y prohibir financiamientos federales de investigación con tejidos fetales obtenidos de abortos voluntarios, debido a que estos fondos obtenidos de los impuestos de los ciudadanos apoya indirectamente la práctica del aborto.

\footnotetext{
${ }^{4}$ Según el Reporte Oficial del Congreso “La administración de Obama ha negado o amenazado con negar la financiación federal de Medicaid a los estados que han intentado retener el reembolso de Medicaid a los proveedores de servicios de aborto" (U.S. House of Representatives. Selective Investigative Panel of The Energy \& Commerce Committee, 2016, pág. xxiii)
}

(3) Mejora de la Investigación Biomédica: Según la investigación que realizó el Panel Selecto, observaron que investigaciones subsidiadas por el $\mathrm{NIH}$ sólo $0.2 \%$ usan tejidos fetales humanos, y sólo un cuarto de estos realmente requieren tejidos fetales humanos para realizar las investigaciones, ya que su uso no es el más apropiado para el modelo experimental propuesto. Sugieren que los modelos experimentales deben ser decididos por criterios científicos más no por conveniencia ni por costo (ya que los tejidos humanos adultos son más costosos y difíciles de encontrar).

\section{Bibliografía}

(C) The Center for Medical Progress. (2015).

Estados Unidos. Recuperado de

http://www.centerformedicalprogress.org

(c) The Center for Medical Progress. (2015).

Human Capital an investigative journalism study by CMP. Estados Unidos.

Recuperado de

http://www.centerformedicalprogress.org /human-capital/

(C) The Center for Medical Progress. (2015). Investigative Footage. Estados Unidos. Recuperado de http://www.centerformedicalprogress.org /cmp/investigative-footage/

Agulles Simó, P., \& Gillén Pascual, M. (2011). Ética de la Investigación Biomédica: Trasplantes, Vacunas y Embriones. Valencia: Editorial cultural y espiritual popular S.L.

Bernal, C. A. (2016). Metodologia de la Investigación (3 ed.). Bogotá: Pearson Educación. 
Blackmun, H. A., \& Supreme Court of the United States. (1972). U.S. Reports: Doe v. Bolton 410 U.S. 179. [Periodical] Recuperado de Library of Congress, https://www.loc.gov/item/usrep410179/.

Blackmun, H. A., \& Supreme Court of the United States. (1972). U.S. Reports: Roe v. Wade 410 U.S. 113. [Periodical]. Recuperado de Library of Congress, https://www.loc.gov/item/usrep410113/.

Breyer, S. G., \& Supreme Court of the United States. (2000). U.S. Reports: Stenberg, Attorney General of Nebraska, et al. v. Carhart, 530 U.S. 914. [Periodical]. Recuperado de Library of Congress, https://www.loc.gov/item/usrep530914/.

Cornell University Law School. (1971-1973). Supreme Court of the United States of America. Doe vs. Bolton 410 U.S. 179. Recuperado de https://www.law.cornell.edu/supremecour t/text/410/179

Cornell University Law School. (1971-1973). Supreme Court of the United States of America. Roe vs. Wade 410 U.S. 113. Recuperado de https://www.law.cornell.edu/supremecour t/text/410/113\%26amp

Cornell University Law School. (2006-2007). Supreme Court of the United States of America. Gonzales vs Carhart 550 U.S. 124. Recuperado de https://www.law.cornell.edu/supremecour t/text/05-380

Cornell's Legal Information Institute (LII), Justia, y Chicago-Kent College of Law. Oyez. (s.f.). Body Politic. The Supreme Court and Abortion Law. Roe v. Wade. Estados Unidos. Recuperado de https://www.oyez.org/cases/1971/70-18
Cornell's Legal Information Institute (LII), Justia, y Chicago-Kent College of Law. Oyez. (s.f.). Body Politic. The Supreme Court and Abortion Law. Planned Parenthood of Southeastern Pennsylvania v. Casey. Estados Unidos. Recuperado de https://www.oyez.org/cases/1991/91-744

Cornell's Legal Information Institute (LII), Justia, y Chicago-Kent College of Law. Oyez. (s.f.). Body Politic. The Supreme Court and Abortion Law. Stenberg v. Carhart. Estados Unidos. Recuperado de https://www.oyez.org/cases/1999/99-830

Cornell's Legal Information Institute (LII), Justia, y Chicago-Kent College of Law. Oyez. (s.f.). Body Politic. The Supreme Court and Abortion Law. Gonzales v. Carhart. Estados Unidos. Recuperado de https://www.oyez.org/cases/2006/05-380

Cornell's Legal Information Institute (LII), Justia, y Chicago-Kent College of Law. Oyez. (s.f.). Body Politic. The Supreme Court and Abortion Law. Ch. 1. Roe v. Wade. Estados Unidos. Recuperado de https://projects.oyez.org/body-politic/ch1

Fox News. (2017). ObamaCare replacement bill approved in House. Recuperado de http://www.foxnews.com/politics/2017/05 /04/obamacare-replacement-billapproved-in-house.html

Hernandez Sampieri, R. (2014). Metodología de la investigación. (6 ed.). Mexico: McGrawHill.

Kaplan, T., \& Pear, R. (4 de Mayo de 2017). House Passes Measure to Repeal and Replace the Affordable Care Act. The New York Times. Recuperado de https://www.nytimes.com/2017/05/04/us/ politics/health-care-bill-vote.html?_r=0; 
May, W. E. (2013). Catholic Bioethics and the Gift of Human Life. . Estados Unidos: Our Sunday Visitor Inc. .

O'Connor, S. D., Kennedy, A. M., Souter, D. H., \& Supreme Court of the United States. (1992). U.S. Reports: Planned Parenthood of Southeastern Pennsylvania v. Casey, 505 U.S. 833. [Periodical] Recuperado de Library of Congress, https://www.loc.gov/item/usrep505833/.

Sgreccia, E. (2014). Manual de Bioética:

Fundamentos y ética biomédica. Madrid:

BAC.

U.S Congress. (2017). H.R.1628 - American

Health Care Act of 2017. 115th Congress.

Recuperado de https://www.congress.gov/bill/115thcongress/house-bill/1628

U.S. House of Representatives. Selective Investigative Panel of The Energy \& Commerce Committee. (2016). Select Investigative Panel Final Report.

Recuperado de https://energycommerce.house.gov/newscenter/letters/select-investigative-panelfinal-report 